\title{
Diagnosing adrenal insufficiency using ACTH stimulation test
}

To the Editor:

We read with interest the real-world data of NANZER et al. [1], looking at adrenal insufficiency (AI) in severe asthma patients taking oral corticosteroid-sparing anti-interleukin (IL)-5 therapy. They reported that $43 \%$ of patients apparently failed a short adrenocorticotropic hormone (ACTH) stimulation test associated with a median baseline morning serum cortisol of $86 \mathrm{nmol} \cdot \mathrm{L}^{-1}$ and a median prednisolone dose of $5 \mathrm{mg}$. We would be interested to know the mean cortisol level after ACTH, as well as the percentage of patients who failed to achieve a post-ACTH level of $500 \mathrm{nmol} \cdot \mathrm{L}^{-1}$ which is the accepted cut-off for impaired response $[2,3]$. Pointedly they used a pharmacological $250 \mu \mathrm{g}$ dose of ACTH instead of the more physiological $0.5-1 \mu \mathrm{g}$ dose $[3,4]$. We suggest that using the correct ACTH dose in conjunction with a $500 \mathrm{nmol} \cdot \mathrm{L}^{-1}$ cortisol cut off would be accompanied by a higher proportion of patients designated with AI. Finally, we also note that their patients were taking high-dose inhaled corticosteroid at a fluticasone propionate equivalent dose of $1 \mathrm{mg} \cdot \mathrm{day}^{-1}$. In this regard, $1 \mathrm{mg}$ of inhaled fluticasone propionate exhibits a cortisol suppressive potency equivalent to $8.5 \mathrm{mg}$ of oral prednisolone [5]. Hence, while it might have been possible to wean the prednisolone dose to $5 \mathrm{mg}$ on anti-IL-5, in reality patients were likely to have been exposed to a much higher total systemic corticosteroid burden.

\section{@ERSpublications}

Low dose ACTH stimulation test is more likely to detect adrenal insuffiency in patients being weaned off oral corticosteroids https://bit.ly/2XsMA3i

Cite this article as: Lipworth B, Chan R, Kuo CRW. Diagnosing adrenal insufficiency using ACTH stimulation test. Eur Respir J 2020; 56: 2001478 [https://doi.org/10.1183/13993003.01478-2020].

Brian Lipworth, Rory Chan and Chris RuiWen Kuo

Scottish Centre for Respiratory Research, University of Dundee, Ninewells Hospital and Medical School, Dundee Scotland, UK.

Correspondence: Brian Lipworth, Scottish Centre for Respiratory Research, University of Dundee, Ninewells Hospital and Medical School, Dundee, DD1 9SY, Scotland, UK. E-mail: b.j.lipworth@dundee.ac.uk

Received: 29 April 2020 | Accepted: 19 May 2020

Conflict of interest: B. Lipworth reports equipment from GSK, grants, personal fees for advisory board work, consultancy and lectures, and non-financial support for meeting attendance from AstraZeneca and Teva, personal fees for consultancy from Lupin, Glenmark, Vectura, Dr Reddy and Sandoz, during the conduct of the study; grants, personal fees for consultancy and lectures, and non-financial support for meeting attendance from Boehringer Ingelheim, grants and personal fees for advisory board work, consultancy and lectures from Mylan, grants and personal fees for advisory board work and consultancy from Sanofi Regeneron, outside the submitted work; and has a family member who is an employee of AstraZeneca. R. Chan has nothing to disclose. C.R.W. Kuo reports personal fees for meeting attendance from AstraZeneca, personal fees for meeting attendance and lectures from Chiesi, personal fees for advisory board work from Circassia, outside the submitted work.

\section{References}

1 Nanzer AM, Chowdhury A, Raheem A, et al. Prevalence and recovery of adrenal insufficiency in steroid-dependent asthma patients receiving biologic therapy. Eur Respir J 2020; 56: 1902273.

2 Wilson AM, McFarlane LC, Lipworth BJ. Effects of low and high doses of inhaled flunisolide and triamcinolone acetonide on basal and dynamic measures of adrenocortical activity in healthy volunteers. J Clin Endocrinol Metab 1998; 83: 922-925.

3 Broide J, Soferman R, Kivity S, et al. Low-dose adrenocorticotropin test reveals impaired adrenal function in patients taking inhaled corticosteroids. J Clin Endocrinol Metab 1995; 80: 1243-1246.

4 Rasmuson S, Olsson T, Hagg E. A low dose ACTH test to assess the function of the hypothalamic-pituitary-adrenal axis. Clin Endocrinol (Oxf) 1996; 44: 151-156.

5 Wilson AM, Lipworth BJ. Short-term dose-response relationships for the relative systemic effects of oral prednisolone and inhaled fluticasone in asthmatic adults. Br J Clin Pharmacol 1999; 48: 579-585. 


\section{From the authors:}

We acknowledge B. Lipworth's work and significant contribution in highlighting the metabolic consequences of steroid therapy in airways disease over the past decades. In their letter he and colleagues refer to a post-synthetic adrenocorticotropic hormone (ACTH, Synacthen) cortisol level of $500 \mathrm{nmol} \cdot \mathrm{L}^{-1}$ as the accepted cut-off to diagnose impaired adrenal function. These diagnostic values were derived using older cortisol assays; however, the cortisol levels in our report relate specifically to the newer Roche Elecsys II Cortisol assay used at our centre that gives, on average, $25 \%$ lower serum cortisol values, with a cut-off of $\geqslant 420 \mathrm{nmol} \cdot \mathrm{L}^{-1}$ for the $250 \mu \mathrm{g}$ intramuscular short Synacthen test (SST) at 30 or $60 \mathrm{~min}$ [1]. The median cortisol level after SST was $490 \mathrm{nmol} \cdot \mathrm{L}^{-1}$ (interquartile range (IQR) $453-620 \mathrm{nmol} \cdot \mathrm{L}^{-1}$ ) in patients who passed the SST; in those who failed the SST the cortisol level after SST was $262 \mathrm{nmol} \cdot \mathrm{L}^{-1}$ (IQR 130$\left.310 \mathrm{nmol} \cdot \mathrm{L}^{-1}\right)$.

An agreed lower reference limit for a post-SST cortisol to specifically define a normal axis or sensitively diagnose adrenal failure depends on the specific assay, timing of sampling, and on population characteristics including body size [2]. Further, values over time have tended to decrease as assay methodologies have improved, measuring cortisol more accurately.

We chose the SST, as opposed to the $1 \mu \mathrm{g}$ Synacthen test (LD-SST), as the SST has been more widely validated against the gold standard insulin tolerance test and represents the most widely used test for diagnosing adrenal insufficiency should the morning cortisol warrant further testing [3]. The SST obviates the need to dilute the Synacthen, which comes in vials of $250 \mu \mathrm{g}$, reducing one potential source of error. The diagnostic levels for cortisol after LD-SST are generally lower to diagnose adrenal failure or identify normality. How important the dose is considering normal physiology is moot, that teams use a reproducible test and interpret it correctly is, we argue, more important.

B. Lipworth and colleagues point out that all of our patients were taking high-dose inhaled corticosteroids, likely resulting in systemic absorption with the potential to affect the hypothalmo-pituitary-adrenal axis; whilst the authors and others have previously shown that systemic effects are less frequently seen in severe asthma patients, compared to healthy individuals $[4,5]$, we attempted to reduce this possible effect further and patients were asked to withhold their inhaled steroid $>12 \mathrm{~h}$ prior to their SST. However, we agree with B. Lipworth and colleagues on the importance of recognising that any synthetic glucocorticosteroid has the potential to lead to adrenal suppression and patients always ought to be informed of this risk, and physicians must prescribe the lowest dose required to safely manage the disease.

\section{@ERSpublications}

When to wean? Steroid stewardship in the biologic era

https://bit.ly/3cOL94R

Cite this article as: Nanzer AM, D'Ancona G, Kelly PA, et al. Diagnosing adrenal insufficiency using ACTH stimulation test. Eur Respir J 2020; 56: 2002149 [https://doi.org/10.1183/13993003.02149-2020].

Alexandra M. Nanzer ${ }^{1,2}$, Grainne D'Ancona ${ }^{1}$, Philip A. Kelly ${ }^{3}$ and David J. Jackson $\oplus^{1,2}$

${ }^{1}$ Guy's and St Thomas' NHS Foundation Trust, Thoracic Medicine, Guy's Severe Asthma Service, London, UK. ${ }^{2}$ King's College London, London, UK. ${ }^{3}$ King's College Hospital NHS Foundation Trust, London, UK.

Correspondence: Alexandra M. Nanzer, Guy's and St Thomas' NHS Foundation Trust, Thoracic Medicine, Guy's Severe Asthma Service, Guy's Hospital, Great Maze Pond, London SE1 9RT, UK. E-mail: alexandra.nanzerkelly@gstt.nhs.uk

Received: 4 June 2020 | Accepted: 5 June 2020

Conflict of interest: A.M. Nanzer reports personal fees for lectures from Teva, personal fees for lectures and travel support from AstraZeneca, personal fees for meeting attendance from Napp, outside the submitted work. G. D'Ancona reports personal fees from Teva, AstraZeneca, GSK, Boehringer Ingelheim and Chiesi, outside the submitted work. P.A. Kelly has nothing to disclose. D.J. Jackson reports personal fees from AstraZeneca, GSK, Teva, Sanofi and Novartis, outside the submitted work.

\section{References}

1 Raverot V, Richet C, Morel Y, et al. Establishment of revised diagnostic cut-offs for adrenal laboratory investigation using the new Roche Diagnostics Elecsys((R)) Cortisol II assay. Ann Endocrinol (Paris) 2016; 77: 620-622.

2 Cartaya J, Misra M. The low-dose ACTH stimulation test: is 30 minutes long enough? Endocr Pract 2015; 21: 508-513. 
3 Stewart PM, Corrie J, Seckl JR, et al. A rational approach for assessing the hypothalamo-pituitary-adrenal axis. Lancet 1988; 1: 1208-1210.

4 Harrison TW, Wisniewski A, Honour J, et al. Comparison of the systemic effects of fluticasone propionate and budesonide given by dry powder inhaler in healthy and asthmatic subjects. Thorax 2001; 56: 186-191.

5 Lee DK, Bates CE, Currie GP, et al. Effects of high-dose inhaled fluticasone propionate on the hypothalamic-pituitary-adrenal axis in asthmatic patients with severely impaired lung function. Ann Allergy Asthma Immunol 2004; 93: 253-258. 